\title{
Long non-coding RNA mortal obligate RNA transcript inhibits the migration and invasion of colon cancer cells by inactivating transforming growth factor $\beta 1$
}

\author{
TAICHENG ZHOU ${ }^{1 *}$, LILI WU ${ }^{2 *}$, ZHEN ZONG $^{3 *}$, NING MA $^{1}$, YINGRU LI ${ }^{1}$, \\ ZHIPENG JIANG ${ }^{1}$, QIRUI WANG ${ }^{4}$ and SHUANG CHEN ${ }^{1}$
}

\begin{abstract}
${ }^{1}$ Department of Gastroenterological Surgery and Hernia Center, The Sixth Affiliated Hospital of Sun Yat-Sen University, Guangdong Provincial Key Laboratory of Colorectal and Pelvic Floor Disease, Guangzhou, Guangdong 510655;

${ }^{2}$ Department of Ultrasonology, The Third Affiliated Hospital of Sun Yat-Sen University, Guangzhou, Guangdong 510630;

${ }^{3}$ Department of Gastroenterological Surgery, The Second Affiliated Hospital of Nanchang University, Nanchang, Jiangxi 510655; ${ }^{4}$ Department of Molecular Biology, State Administration of Traditional Chinese Medicine of the People's Republic of China, School of Traditional Chinese Medicine, Southern Medical University, Guangzhou, Guangdong 510515, P.R. China
\end{abstract}

Received December 16, 2018; Accepted September 26, 2019

DOI: $10.3892 / \mathrm{ol} .2019 .11189$

\begin{abstract}
Long non-coding (lnc)RNA mortal obligate RNA transcript (MORT) is inhibited in numerous types of cancer in humans, indicating its role as a tumor suppressor. The present study demonstrated downregulation of lncRNA MORT in the tumor tissues of patients with colon cancer. The expression of MORT in tumor tissues was linearly associated with its expression levels in plasma. Low MORT expression was associated with low overall survival rate. Moreover, the overexpression of MORT resulted in decreased, whereas treatment with transforming growth factor $\beta 1$ (TGF- $\beta 1$ ) resulted in increased, invasion and migration rates of colon cancer cells. In addition, TGF- $\beta 1$ treatment attenuated the inhibitory effect of MORT overexpression on the invasion and migration rates
\end{abstract}

Correspondence to: Dr Qirui Wang, Department of Molecular Biology, State Administration of Traditional Chinese Medicine of the People's Republic of China, School of Traditional Chinese Medicine, Southern Medical University, 1838 North Guangzhou Avenue, Guangzhou, Guangdong 510515, P.R. China

E-mail: cal5415@163.com

Dr Shuang Chen, Department of Gastroenterological Surgery and Hernia Center, The Sixth Affiliated Hospital of Sun Yat-Sen University, Guangdong Provincial Key Laboratory of Colorectal and Pelvic Floor Disease, 26 Yuancun Erheng Road, Tianhe, Guangzhou, Guangdong 510655, P.R. China

E-mail: ux47154@163.com

${ }^{*}$ Contributed equally

Key words: colon cancer, long non-coding RNA mortal obligate RNA transcript, transforming growth factor $\beta 1$, prognosis of colon cancer cells. The overexpression of MORT inhibited TGF- $\beta 1$ expression in colon cancer cells, whereas treatment with TGF- $\beta 1$ failed to affect the expression of the lncRNA. Therefore, it is postulated that MORT inhibits invasion and migration colon cancer cells by inactivating TGF- $\beta 1$.

\section{Introduction}

Genome-wide transcriptome analysis has revealed that the majority ( $>98 \%)$ of human genes are non-protein coding genes $(1,2)$. Non protein-coding genes transcribe non-coding RNAs (ncRNAs) that participate directly in developmental and differential processes by regulating gene expression at multiple levels, such as at post-transcriptional, translational and epigenetic levels (3). Long ncRNAs (lncRNAs) are a subgroup of ncRNAs that are longer than 200 nucleotides (4). Most of the characterized IncRNAs are specifically expressed in certain types of cells and tissues (5). However, IncRNAs can also enter the circulating system to achieve systemic regulation of gene expression. Thus, certain circulating lncRNAs may be reflected in the RNA levels of lesions (6), indicating their potential role as biomarkers for diseases. At present, the functions of most lncRNAs remain unknown.

Colon cancer is one of the most commonly diagnosed malignancies (7). Colon cancer causes $>60,000$ deaths and $>130,000$ new cases are reported every year in the United States (8). The 5 -year survival rate of patients with colon cancer at the early stages following active treatment is $>70 \%(9,10)$. However, the treatment outcomes of patients at the advanced stages remain poor due to the lack of radical treatment $(9,10)$. Therefore, novel therapeutic targets and prognostic markers are required. The lncRNA mortal obligate RNA transcript (MORT) is inhibited in numerous types of cancer in humans, such as ovarian cancer and gastric cancer (11), indicating its role as a tumor suppressor. The present study investigated the involvement of lncRNA 
MORT in colon cancer and observed its downregulation and its association with prognosis. A primary aim of the present study was to investigate the interaction between MORT and TGF- $\beta$ signaling, which mediates diverse functions in cancer biology by interacting with multiple downstream pathways and regulating cancer cell behaviors $(12,13)$.

\section{Materials and methods}

Patients and follow-up. The present study included 68 patients with colon cancer, who were admitted to The Sixth Affiliated Hospital of Sun Yat-sen University between July 2011 and July 2013. The inclusion criteria were: i) Colon cancer diagnosed by pathological biopsies; ii) understanding of the experimental principle and willingnes to participate; and iii) informed consent. The exclusion criteria were: Patients i) with other diseases; ii) who failed to complete the 5-year follow-up; and iii) who died due to other causes during follow-up. Follow-up was performed via telephone, every month for 5 years following admission. The patients included 12 individuals at stage I, 18 at stage II, 20 at stage III and 18 at stage IV, according to the staging guidelines of the American Joint Committee on Cancer (14). There were 39 males and 29 females with a mean age of $48.6 \pm 4.4$ years (range, 32-66 years). Patients were treated with surgical resections and/or chemotherapy according to their disease conditions. The Ethics Committee of The Sixth Affiliated Hospital of Sun Yat-Sen University approved this study.

Specimens and cell line. Tumor and adjacent (collected $\leq 3 \mathrm{~cm}$ from the tumor border) tissues were obtained from all patients using fine needle biopsies under the guidance of MRI. Blood $(5 \mathrm{ml})$ was extracted from each patient into EDTA-treated tubes one day after admission under fasting conditions. The blood-collection tubes were centrifuged at $1,200 \mathrm{x} \mathrm{g}$ for $20 \mathrm{~min}$ at room temperature to isolate the plasma from the blood. All samples were stored in a liquid nitrogen sink at $-80^{\circ} \mathrm{C}$ before use.

The colon cancer RKO cell line (American Type Culture Collection) was used and cultured in Eagle's Minimum Essential medium (MEM; Sigma-Aldrich; Merck KGaA) supplemented with 10\% FBS (Sigma-Aldrich; Merck KGaA) at $5 \% \mathrm{CO}_{2}$ and $37^{\circ} \mathrm{C}$.

Cell transfection. PcDNA3.1 vectors expressing MORT (NCBI accession no.; NR_036521.1) were designed and constructed by Sangon Biotech Co., Ltd. Lipofectamine ${ }^{\circledR} 2000$ reagent (Invitrogen; Thermo Fisher Scientific, Inc.) was used to transfect $10 \mathrm{nM}$ vectors into $1 \times 10^{6}$ cells. The non-transfected cells were the control cells $(\mathrm{C})$ and cells transfected with the empty vector were the negative control (NC) cells. Cells were harvested $24 \mathrm{~h}$ after transfection to perform subsequent experiments.

Total RNA extraction and reverse transcription-quantitative $(R T-q) P C R$. Tissues were ground and mixed with RNAzol reagent (Sigma-Aldrich; Merck KGaA) to extract total RNA. The RNAzol reagent was also directly mixed with plasma from patients and cells cultured in vitro to extract total RNA. Furthermore, exogenous treatment with TGF- $\beta 1$ (Sigma-Aldrich; Merck KGaA) at doses of 5, 10 and $20 \mathrm{ng} / \mathrm{ml}$

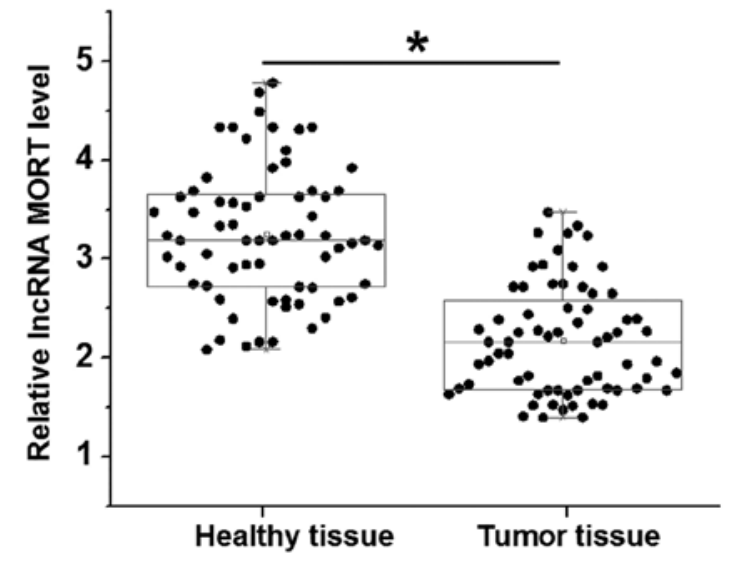

Figure 1. LncRNA MORT is downregulated in colon cancer. Reverse transcription-quantitative PCR results demonstrate significantly decreased expression levels of lncRNA MORT in tumor tissues compared with adjacent healthy tissues. ${ }^{*} \mathrm{P}<0.05$. LncRNA, long non-coding RNA; MORT, mortal obligate RNA transcript.

at $37^{\circ} \mathrm{C}$ for $24 \mathrm{~h}$ was performed in certain cases, prior to RNA extraction. SuperScript IV Reverse Transcriptase (Thermo Fisher Scientific, Inc.) was used to perform RT. The thermal protocol for the reverse transcription stage was $52^{\circ} \mathrm{C}$ for $30 \mathrm{~min}$, followed by $80^{\circ} \mathrm{C}$ for $10 \mathrm{~min}$. In order to detect IncRNA MORT and transforming growth factor $\beta 1$ (TGF- $\beta 1$ ) mRNA, qScript One-Step RT-qPCR kit (Quantabio) was used to prepare the qPCR mixture. The ABI 7500 system was used to carry out all qPCR reactions with GAPDH as the endogenous control. Thermocycling conditions for the PCR reactions were: $95^{\circ} \mathrm{C}$ for $1 \mathrm{~min}$, followed by 40 cycles of $95^{\circ} \mathrm{C}$ for $10 \mathrm{sec}$ and $60^{\circ} \mathrm{C}$ for $35 \mathrm{sec}$. Primers of lncRNA MORT, TGF- $\beta 1$ and GAPDH were obtained from Sangon Biotech Co., Ltd. MORT and TGF- $\beta 1$ were normalized to GAPDH, according to the $2^{-\Delta \Delta C q}$ method (15). The primer sequences were: MORT forward, 5'-GTGTCCGCCATA AAGTCG TT-3'; MORT reverse, 5'-CTGCTATCATTCGCCATGAC-3'; TGF- $\beta 1$ forward, 5 '-AAGAAGTCACCCGCGTGCTA-3'; TGF- $\beta 1$ reverse, 5'-TGTGTGATGTCTTTGGTTTTGTCA-3'; GAPDH forward, 5'-CTGCACCACCAACTGCTTAC-'3; and GAPDH reverse, 5'-CAGAGGTGCCATCCAGAGTT-3'.

Measurement of cell migration and invasion rates. Transwell inserts ( $8 \mu \mathrm{l}$, Corning) were used to analyze cell invasion and migration. Cells collected $24 \mathrm{~h}$ after transfection were mixed with serum-free MEM (Sigma-Aldrich; Merck KGaA) to prepare a single-cell suspension at a concentration of $5 \times 10^{4}$ cells $/ \mathrm{ml}$. The cell suspensions were added to upper chamber of the 96 -well plate $(0.1 \mathrm{ml}$ per well). MEM $(20 \%$ FBS; Sigma-Aldrich; Merck KGaA) was used to fill the lower chamber. In order to mimic cell invasion in vivo, Matrigel (Merck KGaA) was used to coat the membrane of the upper chamber at $37^{\circ} \mathrm{C}$ for $12 \mathrm{~h}$ prior to performing the invasion assay. Uncoated membranes were used for migration assay, but the same protocol was followed. The plate was incubated at $37^{\circ} \mathrm{C}$ in $5 \% \mathrm{CO}_{2}$ for $2 \mathrm{~h}$. Subsequently, the upper chamber membranes were stained at $25^{\circ} \mathrm{C}$ for 90 min with $0.5 \%$ crystal violet (Sigma-Aldrich; Merck KGaA). An optical microscope was used to count the stained cells (magnification, $\mathrm{x} 40$ ). 
A

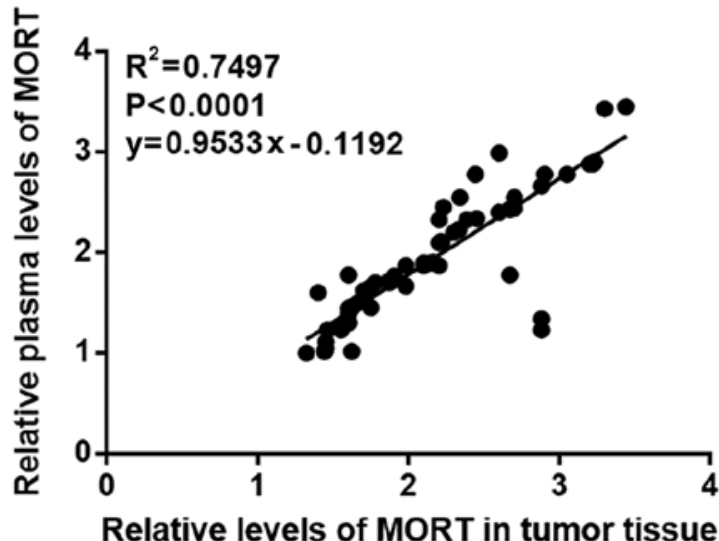

B

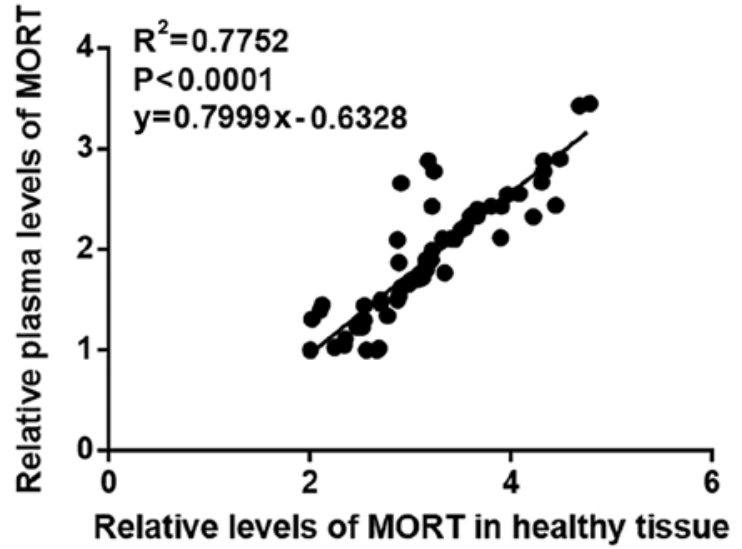

Figure 2. Expression level of MORT in tissues is linearly associated with plasma levels. Linear regression analysis demonstrated an association between the expression levels of MORT in (A) tumor tissues and (B) healthy tissues with the plasma levels in patients with colon cancer. MORT, mortal obligate RNA transcript.

Western blot assay. RIPA buffer (Invitrogen; Thermo Fisher Scientific, Inc.) was used for total protein extraction, and the BCA assay (Invitrogen; Thermo Fisher Scientific, Inc.) was used for protein quantification. To denature proteins, protein samples were incubated with boiling water for $10 \mathrm{~min}$. After that, $10 \%$ SDS-PAGE was used to separate proteins $(30 \mu \mathrm{g}$ per lane) and proteins were transferred to PVDF membranes. PBS (Sigma-Aldrich; Merck KGaA) containing 5\% non-fat milk was used to coat membranes at room temperature for 2 h. After that, GAPDH (1:1,000; cat. no. ab9845; Abcam) and TGF- $\beta 1$ (1:1,000; cat. no. ab92486; Abcam) primary antibodies were used to incubate the membranes for $12 \mathrm{~h}$ at $4^{\circ} \mathrm{C}$, followed by incubation with secondary goat anti-rabbit (horseradish peroxidase, 1:1,000; cat. no. ab6721; Abcam) for $2 \mathrm{~h}$ at room temperature. Enhanced chemiluminescence system (ECL; GE Healthcare) was used for signal production. All signals were analyzed using Quantity One software v.4.6 (Bio-Rad Laboratories, Inc.).

Statistical analysis. Experiments were repeated three times to calculate mean values \pm standard deviation. Prism 6.01 software (GraphPad Software, Inc.) was used to carry out all statistical analyses. The association between the expression level of MORT in the biopsies and plasma of patients with colon cancer was analyzed using linear regression analysis. The expression of MORT was compared between tumor and healthy tissues using the paired t-test. The associations between clinicopathological factors of patients (age, gender and clinical stages) and the plasma levels of MORT were analyzed using the $\chi^{2}$ test. The expression of TGF- $\beta 1$ and the cell migration and invasion rates were compared among the different groups of transfected cells using one-way ANOVA, followed by Tukey's post hoc test (all data met the assumption of homogeneity of variance). According to the expression levels of IncRNA MORT in tumor tissues, the patients were divided into high- $(n=31)$ and low- $(n=37)$ lncRNA MORT expression groups using the cut-off value of 2.27, identified by Youden's index. Survival curves were plotted for both of these groups, based on the follow-up data, using the Kaplan-Meier plotter (Prism 6; GraphPad Software, Inc.) and were compared with the log rank test.

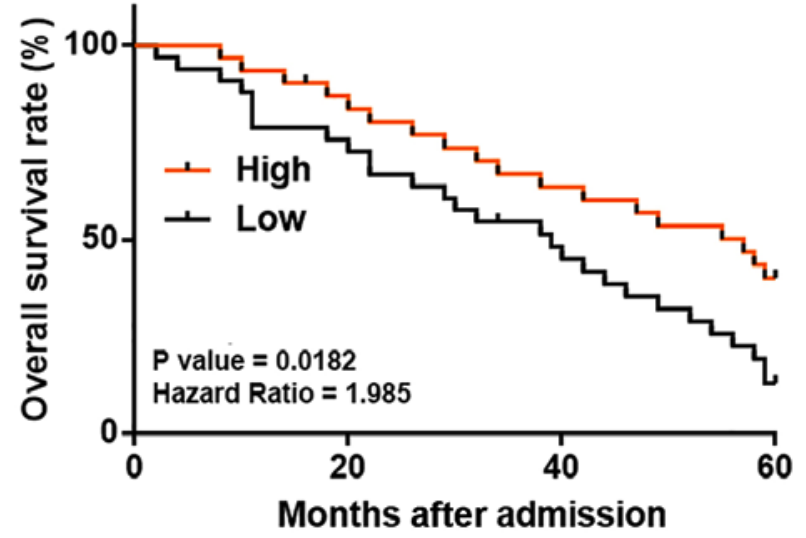

Figure 3. Low MORT plasma levels are associated with low overall survival rate in patients with colon cancer. The Kaplan-Meier survival curve analysis shows significantly lower overall survival rate in patients with low plasma levels of MORT than that those with high plasma levels. MORT, mortal obligate RNA transcript.

$\mathrm{P}<0.05$ was considered to indicate a statistically significant difference.

\section{Results}

LncRNA MORT is downregulated in colon tumor tissues. MORT was detected by RT-qPCR in 68 tumor and adjacent healthy tissues from patients with colon cancer. The differences in the levels of MORT expression between the two types of tissue were analyzed using a paired t-test. Compared with that in the healthy tissues, the expression of MORT was significantly decreased in the tumor samples $(\mathrm{P}<0.05$; Fig. 1$)$. No significant differences were found in the expression levels of MORT, in tumor and healthy tissues, among patients at different clinical stages (data not shown).

The expression level of IncRNA MORT in tissue is linearly associated with plasma levels. The plasma lncRNA MORT levels in 68 patients with colon cancer were measured using RT-qPCR. The association between the expression levels of MORT in the biopsies and plasma of the patients was analyzed by linear regression analysis. As shown in Fig. 2A, MORT 
A

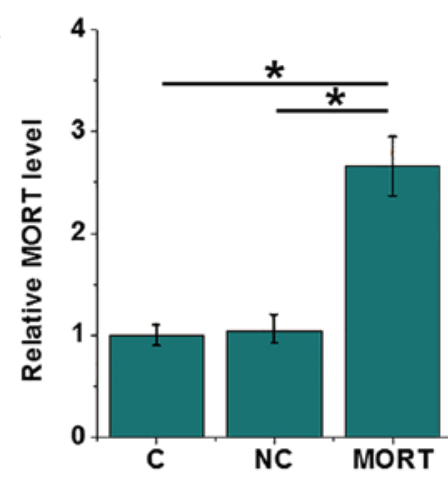

C
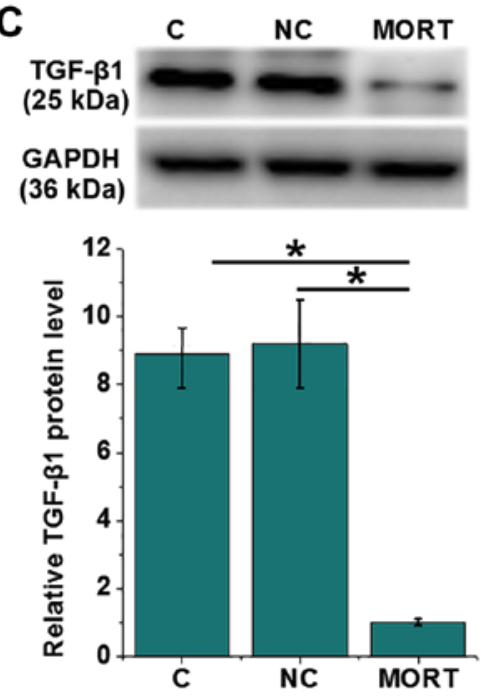

B

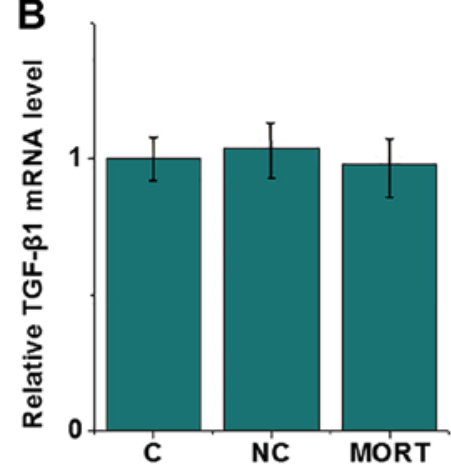

D

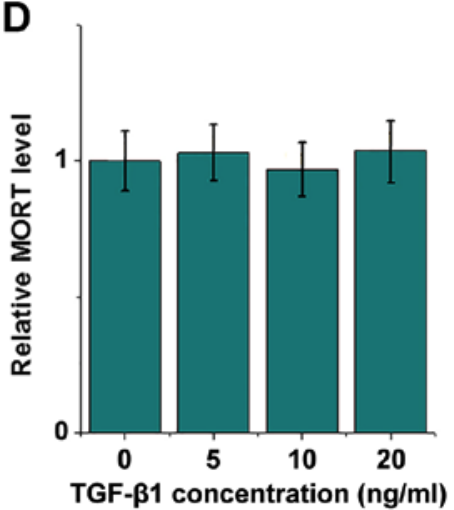

Figure 4. MORT is an upstream inhibitor of TGF- $\beta 1$ in colon cancer RKO cells. (A) Overexpression of MORT was achieved in RKO cells $24 \mathrm{~h}$ after transfection with an overexpression plasmid. (B) TGF- $\beta 1$ expression is not affected at the mRNA level following MORT overexpression. (C) TGF- $\beta 1$ protein levels is significantly decreased at protein level in cells overexpressed with MORT compered with the NC group. (D) Treatment with exogenous TGF- $\beta 1$, at doses of 5,10 and $20 \mathrm{ng} / \mathrm{ml}$ for $24 \mathrm{~h}$, had no significant effect on MORT expression in the cells. Data from 3 biological replicates were expressed as mean \pm standard deviation. " $\mathrm{P}<0.05$. C, control; NC, negative control; MORT, mortal obligate RNA transcript overexpression; TGF, transforming growth factor.

A
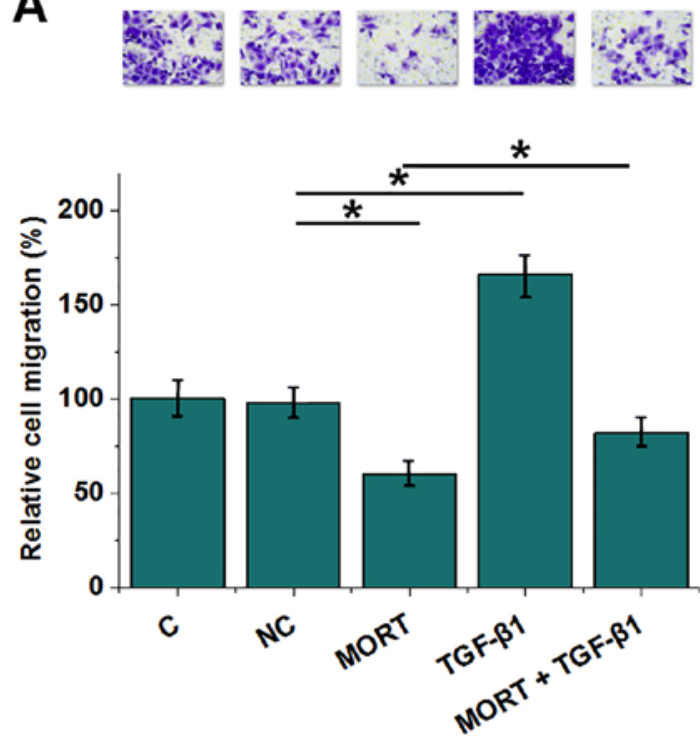

B
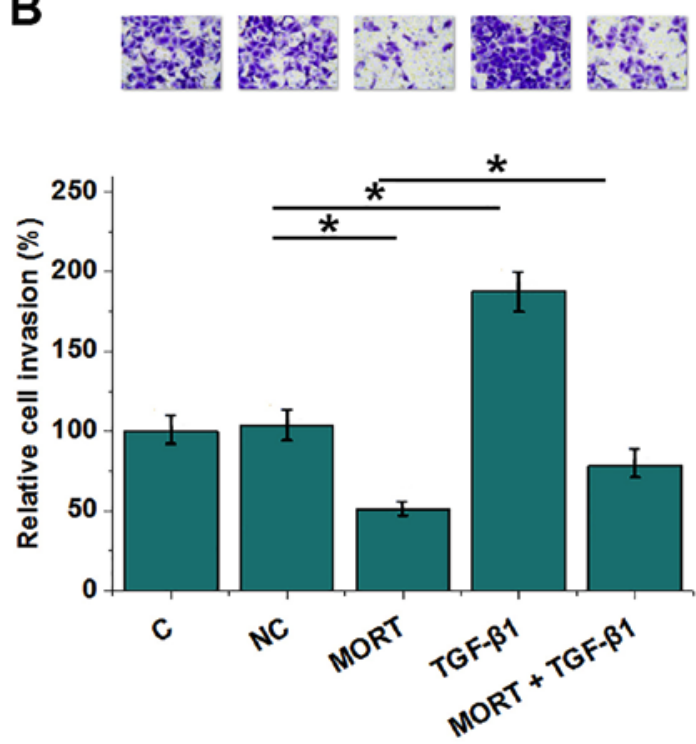

Figure 5. MORT overexpression results in decreased migration and invasion rates in colon cancer RKO cells, possibly by inhibiting TGF- $\beta 1$. MORT overexpression inhibited, whereas treatment with TGF- $\beta 1$ treatment promoted the (A) migration and (B) invasion of RKO cells compared with the NC group. In addition, TGF- $\beta 1$ treatment decreased the inhibitory effect of MORT overexpression. Data from 3 biological replicates were expressed as mean \pm standard deviation values. " $\mathrm{P}<0.05$. C, control; NC, negative control; MORT, mortal obligate RNA transcript; TGF, transforming growth factor. 
expression in tumor tissues was significantly associated with the plasma levels $(\mathrm{P}<0.0001)$. In addition, the expression of MORT in healthy tissues was also significantly associated with the levels in plasma $(\mathrm{P}<0.0001$; Fig. 2B).

Low lncRNA MORT plasma levels are associated with low overall survival $(O S)$ rate in patients with colon cancer. It was observed that the plasma levels of MORT were not significantly associated with the patient age, gender and clinical stage (all $\mathrm{P}>0.05$; data not shown). The patients were divided into high $(n=31)$ and low $(n=37)$ plasma MORT level groups. Kaplan-Meier survival curves were plotted for both groups, based on the follow-up data, and compared using the log rank test. As shown in Fig. 3, the patients with low plasma levels of lncRNA MORT had a significantly lower OS rate.

LncRNA MORT is an upstream inhibitor of TGF- $\beta 1$ in colon cancer RKO cells. The overexpression of MORT was achieved $24 \mathrm{~h}$ after transfection of an overexpression plasmid in RKO cells ( $\mathrm{P}<0.05$; Fig. 4A). Compared with the $\mathrm{C}$ and $\mathrm{NC}$ cells, the overexpression of IncRNA MORT led to no significant difference in the mRNA level of TGF- $\beta 1$ (Fig. 4B), whereas its protein level was significantly decreased ( $\mathrm{P}<0.05$; Fig. 4C). In contrast, exogenous treatment with TGF- $\beta 1$ at doses of 5,10 and $20 \mathrm{ng} / \mathrm{ml}$ for $24 \mathrm{~h}$ had no significant effect on the expression of MORT (Fig. 4D).

Overexpression of LncRNA MORT decreases migration and invasion of RKO cells by inhibiting TGF- $\beta 1$. Compared with the negative control (NC) group, IncRNA MORT overexpression resulted in decreased, whereas TGF- $\beta 1$ treatment resulted in increased rates of migration (Fig. 5A) and invasion (Fig. 5B) of colon cancer cells (all $\mathrm{P}<0.05$ ). In addition, TGF- $\beta 1$ significantly decreased the effects of MORT overexpression $(\mathrm{P}<0.05)$.

\section{Discussion}

At present, the prognosis of patients with colon cancer remains poor, especially for those at advanced stages (7-10). The present study demonstrated downregulation of lncRNA MORT in colon cancer and its association with low OS rate in patients.

TGF- $\beta$ signaling is a well-characterized signaling transduction pathway in cancer biology $(12,13)$. It is generally considered that TGF- $\beta$ signaling activation in most, if not all, types of cancer inhibits tumor cell proliferation at the early stages and promotes tumor metastasis at the later stages $(12,13)$. In clinical practices, TGF- $\beta$ signaling inhibition can also improve cancer treatment outcomes, such as overall survival time (16). However, the activation of TGF- $\beta$ signaling can also promote the development of colon cancer (17). Consistent with previous studies, the present study reported increased migration and invasion of colon cancer cells in response to exogenous TGF- $\beta 1$ treatment. The TGF- $\beta$ pathway participates in cancer biology by regulating downstream signaling molecules, such as lncRNAs (18). The present study suggests that the TGF- $\beta$ pathway may be regulated by the IncRNA MORT.

Several characterized lncRNAs are specifically expressed in certain types of cells and tissues, indicating their specific involvement in certain biological processes (5). However, lncRNAs can also enter the circulating system to regulate gene expression globally (6). The present study detected the expression levels of MORT in both tumor and healthy tissues, which were linearly associated with the plasma levels. This indicates that the IncRNA MORT expressed in tissues may be released into the bloodstream. Therefore, MORT may serve as a regulator of gene expression. The circulating levels of lncRNAs may be used as markers to reflect diseases (6). The findings from the present study suggest MORT as a potential prognostic marker for colon cancer. Therefore, detecting the plasma levels of MORT may be valuable for the design of follow-up care after treatment. However, further clinical studies are required to confirm this hypothesis. A limitation of the present study was that it failed to elucidate the mechanism underlying the interaction between MORT and TGF- $\beta$; consequently, further studies are required to investigate this process.

In conclusion, IncRNA MORT is downregulated in colon cancer and is associated with low OS rate. Moreover, overexpression of 1ncRNA MORT inhibits migration and invasion of colon cancer cells by inhibiting TGF- $\beta$ protein expression.

\section{Acknowledgements}

Not applicable.

Funding

No funding was received.

\section{Availability of data and materials}

The datasets used and/or analyzed during the present study are available from the corresponding author on reasonable request.

\section{Authors' contributions}

TZ, LW and ZZ conducted experiments, analyzed all the data and were major contributors in writing the manuscript. NM, YL and ZJ conducted experiments. QW and SC contributed to the study design. All authors read and approved the final manuscript.

\section{Ethics approval and consent to participate}

Approval was obtained from the Ethics Committee of The Sixth Affiliated Hospital of Sun Yat-Sen University, Guangzhou, China. Written informed consent was provided by all participants.

\section{Patient consent for publication}

Not applicable.

\section{Competing interests}

The authors declare that they have no competing interests. 


\section{References}

1. Mattick JS and Rinn JL: Discovery and annotation of long noncoding RNAs. Nat Struct Mol Biol 22: 5-7, 2015.

2. Rinn JL and Chang HY: Genome regulation by long noncoding RNAs. Annu Rev Biochem 81: 145-166, 2012.

3. Mattick JS: Non-coding RNAs: The architects of eukaryotic complexity. EMBO Rep 2: 986-991, 2001.

4. Mercer TR, Dinger ME and Mattick JS: Long non-coding RNAs: Insights into functions. Nat Rev Genet 10: 155-159, 2009.

5. Iyer MK, Niknafs YS, Malik R, Singhal U, Sahu A, Hosono Y, Barrette TR, Prensner JR, Evans JR, Zhao S, et al: The landscape of long noncoding RNAs in the human transcriptome. Nat Genet 47: 199-208, 2015.

6. Qi P, Zhou XY and Du X: Circulating long non-coding RNAs in cancer: Current status and future perspectives. Mol Cancer 15: 39, 2016.

7. Siegel R, Desantis C and Jemal A: Colorectal cancer statistics, 2014. CA Cancer J Clin 64: 104-117, 2014.

8. Siegel RL, Miller KD, Fedewa SA, Ahnen DJ, Meester RGS Barzi A and Jemal A: Colorectal cancer statistics, 2017. CA Cancer J Clin 67: 177-193, 2017.

9. Liang B, Shahbaz M, Wang Y, Gao H, Fang R, Niu Z, Liu S, Wang B, Sun Q, Niu W, et al: Integrinbeta6-targeted immunoliposomes mediate tumor-specific drug delivery and enhance therapeutic efficacy in colon carcinoma. Clin Cancer Res 21: 1183-1195, 2015.

10. Mannucci S, Ghin L, Conti G, Tambalo S, Lascialfari A, Orlando T, Benati D, Bernardi P, Betterle N, Bassi R, et al: Magnetic nanoparticles from Magnetospirillum gryphiswaldense increase the efficacy of thermotherapy in a model of colon carcinoma. PLoS One 9: e108959, 2014.
11. Vrba L and Futscher BW: Epigenetic silencing of lncRNA MORT in 16 TCGA cancer types. F1000Res 7: 211, 2018.

12. Derynck R, Akhurst RJ and Balmain A: TGF-beta signaling in tumor suppression and cancer progression. Nat Genet 29: 117-129, 2001.

13. Akhurst RJ and Derynck R: TGF-beta signaling in cancer-a double-edged sword. Trends Cell Biol 11: S44-S51, 2001.

14. Hari DM, Leung AM, Lee JH, Sim MS, Vuong B, Chiu CG and Bilchik AJ: AJCC Cancer Staging Manual 7th edition criteria for colon cancer: Do the complex modifications improve prognostic assessment? J Am Coll Surg 217: 181-190, 2013.

15. Livak KJ and Schmittgen TD: Analysis of relative gene expression data using real-time quantitative PCR and the 2(-Delta Delta $\mathrm{C}(\mathrm{T})$ ) method. Methods 25: 402-408, 2001.

16. Colak S and Ten Dijke P: Targeting TGF- $\beta$ Signaling in Cancer. Trends Cancer 3: 56-71, 2017.

17. Peng X, Luo Z, Kang Q, Deng D, Wang Q, Peng H, Wang S and Wei Z: FOXQ1 mediates the crosstalk between TGF- $\beta$ and Wnt signaling pathways in the progression of colorectal cancer. Cancer Biol Ther 16: 1099-1109, 2015.

18. Yuan JH, Yang F, Wang F, Ma JZ, Guo YJ, Tao QF, Liu F, Pan W, Wang TT, Zhou CC, et al: A long noncoding RNA activated by TGF- $\beta$ promotes the invasion-metastasis cascade in hepatocellular carcinoma. Cancer Cell 25: 666-681, 2014.

This work is licensed under a Creative Commons Attribution-NonCommercial-NoDerivatives 4.0 International (CC BY-NC-ND 4.0) License. 